\title{
Function Heterogeneity of Different Segments of Left Ventricle in Pediatric Dilated Cardiomyopathy: A Tissue Doppler Study
}

\author{
Yasser Sedky ${ }^{1}$, Sonia A. EL Saiedi' ${ }^{1}$, Nevin M.M. Habeeb², Rania M.H. El Kaffas' ${ }^{1}$, \\ Mona A. Gabre ${ }^{1}$, Ahmad M. Badr ${ }^{1}$, *Mohamed S. Eid ${ }^{1}$ \\ 1 Department of Pediatrics, Faculty of Medicine, Cairo University, Egypt; ymsedky@hotmail.com, \\ myheartclinic@window slive.com,nevin.habib@yahoo.com, raniaelkaffas@yahoo.com, \\ drmonaahmed11@yahoo.com, abadr2007@yahoo.com,mohamed_samir_eid@cu.edu.eg \\ 2 Department of Pediatrics, Faculty of Medicine, Ain Shams University, Egypt; \\ nevin.habib@yahoo.com \\ * Correspondence: mohamed_samir_eid@cu.edu.eg \\ Received: 8/2/2021; Accepted: 8/4/2021; Published online: 25/6/202.
}

\begin{abstract}
:
Background: Dilated cardiomyopathy (DCM) is characterized by impaired systolic and diastolic function of one or both ventricles.

Aim of the Work: To assess left ventricular (LV) regional systolic as well as global systolic, diastolic functions and desynchrony in children with idiopathic DCM using tissue Doppler imaging.

Materials and Methods: The study comprised 30 patients with idiopathic DCM (4.4+3.3 years) and 10 healthy children as a control group. Electrocardiography (ECG)-gated echocardiography was done using m-mode and conventional Doppler as well as tissue Doppler imaging to obtain modified Tei index, mitral annular wave velocities ( $\mathrm{S}^{\prime}, \mathrm{E}^{\prime}$ and $\mathrm{A}^{\prime}$ ) as well as offline analysis of color tissue velocity imaging to obtain the peak systolic velocities of $12 \mathrm{LV}$ points in apical four chamber, two chamber and long axis views.

Results: The peak systolic velocities of mitral annulus as well as the different LV segments of patients were significantly lower than that of the control group. The E/E' ratio of patients was (11.39+2.4). S' and $\mathrm{E}^{\prime}$ wave of lateral and septal aspects of mitral annulus were correlated. The Tei index of $L V$ of patients $(0.568+0.1136)$ was significantly higher than that of the control group. The averaged mid LV segments showed significantly lower peak systolic velocity $(3.018 \pm 0.777 \mathrm{~cm} / \mathrm{sec})$. There was significant difference between different LV segments as regards the peak systolic velocities $(\mathrm{P}<0.05)$. When comparing the time to peak standard deviation (TPSD) of lateral wall $( \pm 36.071)$ to septal wall $( \pm 33.020)$, no marked difference was detected $(\mathrm{P}>0.05)$. Conclusion: The diastolic dysfunction among children with idiopathic DCM lies in the borderline zone. Systolic and diastolic dysfunctions correlate. There is regional heterogeneity of left ventricular systolic velocities being in general lower in mid segments. No marked left ventricular systolic desynchrony in DCM was found in pediatric age group.
\end{abstract}

Level of Evidence of Study: IIA. (1)

Keywords: Dilated cardiomyopathy; systolic dysfunction; diastolic dysfunction; tissue Doppler imaging; left ventricular segments; desynchrony.

Abbreviations: CRT: cardiac resynchronization therapy; DCM: Dilated cardiomyopathy; EF: ejection fraction; FS: fractional shortening; LVEDD: left ventricular end diastolic diameter; LVESD: Left ventricular end systolic diameter; TDI: tissue Doppler imaging; TP: time to peak; Ts-SD: systolic time standard deviation; Ts-maxD: TVI: tissue velocity imaging

\section{Introduction}

Dilated cardiomyopathy (DCM) is defined by the presence of left ventricular dilatation and left ventricular systolic dysfunction in the absence of abnormal loading conditions or coronary artery disease sufficient to cause global systolic impairment (2). Left ventricular systolic function 
is the most important predictor of long-term prognosis in patients with dilated cardiomyopathy (3). Diastolic dysfunction is an important determinant of dyspnea in patients with dilated cardiomyopathy and relates better with exercise tolerance and clinical events in this population than left ventricular ejection fraction.

Echocardiographic tissue Doppler imaging (TDI) enables the assessment of left and right ventricular mechanics by measuring myocardial velocities and time to peak myocardial velocities with high temporal resolution. The assessment of peak systolic velocities of the left ventricular myocardium with TDI is of incremental value to conventional echocardiography to assess global and regional ventricular performance in various clinical conditions (4). Several studies have demonstrated that not all patients with a wide QRS complex exhibit evidence of mechanical desynchrony. Furthermore, up to $30-50 \%$ of patients with a narrow QRS complex may have mechanical desynchrony measured by echocardiography. Some of these patients with narrow QRS may benefit from cardiac resynchronization therapy (5). The aim of this work was to assess the global systolic and diastolic functions and their relations as well as regional systolic function of left ventricle using the tissue Doppler imaging in children with dilated cardiomyopathy. Left ventricular systolic desynchrony was also investigated.

\section{Subjects and Methods}

This was a prospective study conducted at the Cardiomyopathy Clinic and Echocardiography Laboratory of Children's Hospital, Cairo University. Written consent was obtained from parents or care givers before enrollment in the study, and the study was approved by the ethical committee of Faculty of Medicine, Cairo University.

\section{Participants}

The study comprised 30 children proved to have dilated cardiomyopathy. Patients with fractional shortening less than $30 \%$ and those with left ventricular end diastolic diameter (LVEDD) $\mathrm{Z}$ score $>2$ were included. Patients with congenital or rheumatic heart disease were excluded. All patients were diagnosed as idiopathic dilated cardiomyopathy. At the time of the study all included patients were receiving the standard protocol of treatment which included furosemide, spironolactone, captopril, in addition to digitalis. Ten healthy age and sex matched children were recruited as a control group.

\section{Methods}

All studied patients underwent full history taking and thorough clinical examination. The following was performed to all patients: blood pressure measurement, 12 leads electrocardiography, and electrocardiography- gated echocardiography (using Vivid 7 dimensions, GE, Norway). All readings were adjusted to age and body weight. ECG- gated echocardiography was performed applying the following modalities:

1-M-mode of Left Ventricle (short axis parasternal view): to obtain left ventricular end diastolic diameter (LVEDD), Left ventricular end systolic diameter (LVESD), and to calculate ejection fraction (EF) and fractional shortening (FS). Z-score of left ventricular end diastolic diameter was calculated using the following formula.

Actual value-mean value for age/standard deviation around the mean for age

2-Pulsed Doppler (at tips of mitral valve leaflets in apical four chamber view): to obtain transmitral diastolic flow (E and A waves)

3-Tissue Doppler imaging (TDI) (using Nyquist limit 15-20msec): sector size and depth were adjusted to obtain the highest possible frame rate using the following modes:

A- Pulsed Doppler Tissue Velocity Imaging (TVI): they were sampled at the level of septal and lateral aspects of mitral annulus in apical four chamber view. Value for each component of TVI waves (S', E' and A') were over 3 consecutive cardiac cycles, E/E' was calculated. From the same tracing isovolumetric contraction, isovolumetric relaxation as well as ejection time (systolic wave time) were measured, and the LV Tei index was calculated as follows: Isovolumetric contraction time + Isovolumetric relaxation time/systolic wave time (6). 


\section{B- Color TVI}

Data acquisition was done in apical four chamber, apical two chamber and long axis views, at least three consecutive cardiac cycles were stored. Myocardial pulsed Doppler velocity profile signals were reconstituted offline from TVI color images that provides regional myocardial velocity curves. From the apical 4 chamber, 2 chamber and long axis apical a basal 6 and mid 6 segmental models were obtained in the LV namely septal, lateral, antero-septal, posterior, anterior and inferior segments. They were chosen to give a collective picture of all ventricular walls, as the apical points have large angle of incidence between the cursor and axis of motion thus were ignored. The peak myocardial systolic velocity $\mathrm{Sm}$ was measured (7) per region. The time interval between the onset of the QRS complex and the peak systolic velocity was derived. Left ventricular desynchrony was defined as the maximum delay between peak systolic velocities among the six segments within the LV (8).

Average $\mathrm{S}^{\prime}, \mathrm{E}^{\prime}$ and $\mathrm{A}^{\prime}$ waves and TP in the six mid segments (lateral wall and septal wall in the three views was studied also in the six basal segments. Average $\mathrm{S}^{\prime}, \mathrm{E}^{\prime}$ and A' waves and time to peak (TP) of basal and mid segment in each wall for each view. Data were collected and analyzed using appropriate statistical methods. TP measured from the start of the QRS complex to the peak contraction velocity (9). These methods of tissue Doppler were chosen for assessment according to the availability of this software in our echocardiography laboratory.

\section{Statistical Analysis}

Data were collected and analyzed using appropriate statistical methods. Continuous variables were summarized as mean $\pm \mathrm{SD}$ (standard deviation) or median (range). Interquartile ranges were displayed to minimize the visual effects of infrequent outliers. T test was employed for parametric values and Chi 2 for non-parametric values. Statistical difference was considered significant if value of $\mathrm{p}$ was less than 0.05 .

\section{Results}

The study comprised 30 patients suffering from idiopathic DCM, 16 males and 14 females, the mean of their ages was $52.9 \pm 40.12$ months. Ten healthy children, 4 males and 6 females, were recruited as a control group, the mean of their ages was $80.1 \pm 59.22$ months. Data of echocardiographic assessment of left ventricle by m-mode are presented in table 1 .

Table 1. Comparison between patients and the control group as regards the parameters of echocardiographic assessment of LV by m-mode.

\begin{tabular}{|c|c|c|c|c|c|c|}
\hline & & Mean & SD & Range & Median & $\begin{array}{c}P \\
\text { value }\end{array}$ \\
\hline \multirow{3}{*}{$\begin{array}{l}\text { Z-score of } \\
\text { LVEDD }\end{array}$} & Cases & 4.988 & \pm 2.3104 & $1-9.7$ & 4.56 & \multirow{3}{*}{0.000} \\
\hline & Control & 0.529 & \pm 0.6195 & $-0.3-1.7$ & 0.375 & \\
\hline & Total & 3.873 & \pm 2.8073 & $-0.3-9.7$ & 3.58 & \\
\hline \multirow{3}{*}{ EF\% } & Cases & 47.28 & \pm 10.98 & $32-67$ & 47 & \multirow{3}{*}{0.000} \\
\hline & Control & 67.9 & \pm 6.919 & $54-80$ & 68 & \\
\hline & Total & 52.56 & \pm 13.543 & $32-80$ & 50 & \\
\hline \multirow{3}{*}{ FS\% } & Cases & 23.67 & \pm 6.743 & $15-37$ & 23.5 & \multirow{3}{*}{0.000} \\
\hline & Control & 37.3 & \pm 4.968 & $28-46$ & 37 & \\
\hline & Total & 27.08 & \pm 8.675 & $15-46$ & 25.5 & \\
\hline \multirow{3}{*}{$\begin{array}{l}\text { Mitral E/A } \\
\text { ratio }\end{array}$} & Cases & 1.973 & \pm 0.604 & $1-3.5$ & 1.805 & \multirow{3}{*}{0.851} \\
\hline & Control & 1.899 & \pm 0.4397 & $1.4-2.7$ & 1.83 & \\
\hline & Total & 1.954 & \pm 0.954 & $1-3.5$ & 1.805 & \\
\hline
\end{tabular}

EF: Ejection fraction; FS: Fractional shortening; LVEDD: Left ventricular end diastolic diameter.

Data of pulsed Doppler TVI of septal and lateral aspects of MV are presented in table 2. Patients with DCM displayed borderline diastolic dysfunction as their E/E' ratio $(11.398 \pm 2.45)$ was significantly higher than that of the control group $(8.154 \pm 1.458),(p=0.0001)$. The myocardial performance index of patients $(0.568 \pm 0.1136)$ was significantly higher than that of the control group $(0.353 \pm 0.0523)(p=0.0001)$. 


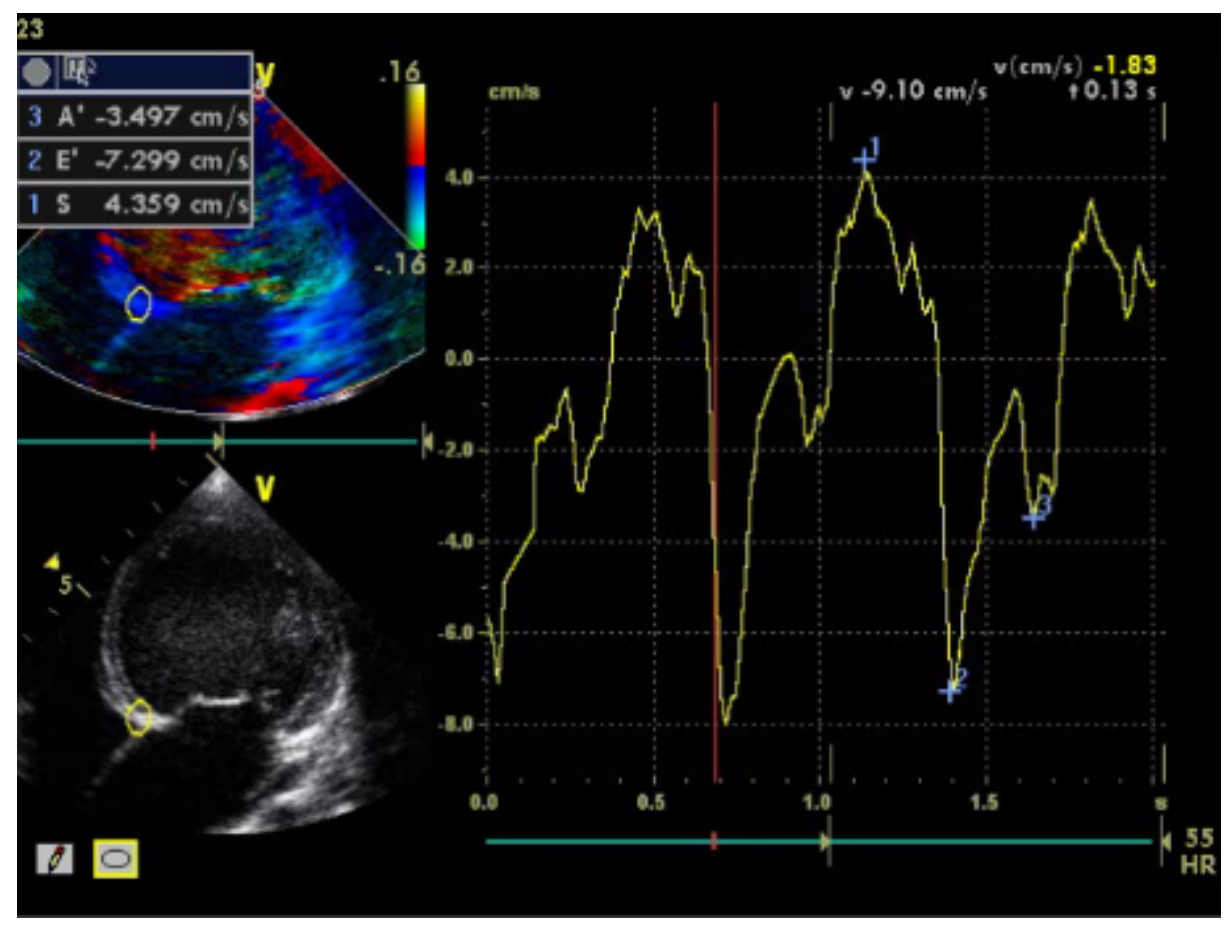

Figure (1): Pulsed wave tissue Doppler imaging at the basal segment of septal wall of left ventricle in 4 chamber apical view showing $\mathrm{S}^{\prime}, \mathrm{E}^{\prime}$ and $\mathrm{A}^{\prime}$ waves.

Table 2. Comparison between patients and the control group as regards the parameters of pulsed Doppler TVI of septal and lateral aspects of mitral valve annulus.

\begin{tabular}{|c|c|c|c|}
\hline & & Mean \pm SD & $\begin{array}{c}P \\
\text { value }\end{array}$ \\
\hline \multirow{2}{*}{ Average mitral S' (cm/s) } & Cases & $5.483 \pm 1.6267$ & \multirow{2}{*}{0.000} \\
\hline & Control & $8.35 \pm 1.9586$ & \\
\hline \multirow{2}{*}{ Lateral mitral S' (cm/s) } & Cases & $5.13 \pm 1.634$ & \multirow{2}{*}{0.001} \\
\hline & Control & $8.7 \pm 3.302$ & \\
\hline \multirow{2}{*}{ Lateral mitral E' (cm/s) } & Cases & $10.13 \pm 3.636$ & \multirow{2}{*}{0.005} \\
\hline & Control & $14.10 \pm 2.807$ & \\
\hline \multirow{2}{*}{ Lateral mitral S'/E' } & Cases & $0.53 \pm 0.1444$ & \multirow{2}{*}{0.21} \\
\hline & Control & $0.612 \pm 0.1741$ & \\
\hline \multirow{2}{*}{ Septal mitral S' (cm/s) } & Cases & $5.83 \pm 2.036$ & \multirow{2}{*}{0.005} \\
\hline & Control & $8 \pm 1.491$ & \\
\hline \multirow{2}{*}{ Septal mitral E' (cm/s) } & Cases & $9.17 \pm 2.866$ & \multirow{2}{*}{0.001} \\
\hline & Control & $12.7 \pm 2.163$ & \\
\hline \multirow{2}{*}{ Septal mitral S'/E' } & Cases & $0.654 \pm 0.1863$ & \multirow{2}{*}{0.963} \\
\hline & Control & $0.636 \pm 0.0858$ & \\
\hline
\end{tabular}

Patients with DCM showed segmental systolic dysfunction. Data of peak systolic velocity of different LV segments of both studied groups are presented in table 3. In patients with DCM the mid segment of LV showed significantly lower peak systolic velocity $(3.018 \pm 0.777 \mathrm{~cm} / \mathrm{sec})$ as compared to the basal segments $(3.785 \pm 0.9771 \mathrm{~cm} / \mathrm{sec})(\mathrm{p}=0.0001)$ (Figure 1). By multivariate analysis there was significant difference between the peak systolic velocities of the six studied walls of left ventricle $(p<0.05)$.

Within the group of DCM there was significant positive correlation between lateral mitral S' and $\mathrm{E}^{\prime}$ waves $(\mathrm{r}=0.687, \mathrm{p}=0.0001)$, as well as septal mitral $\mathrm{S}^{\prime}$ and $\mathrm{E}^{\prime}$ waves $(\mathrm{r}=0.632, \mathrm{p}=0.0001)$ (Figure 2). 


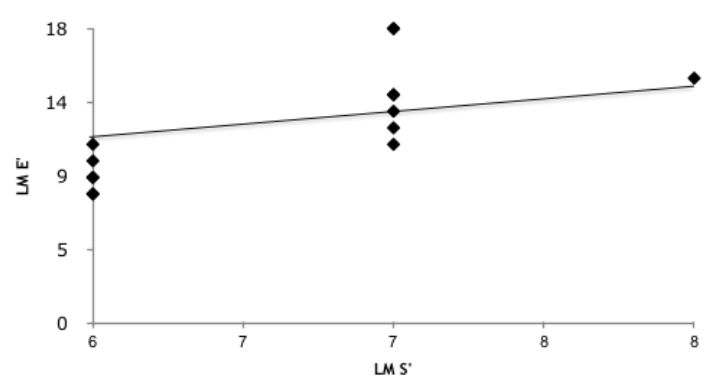

(a)

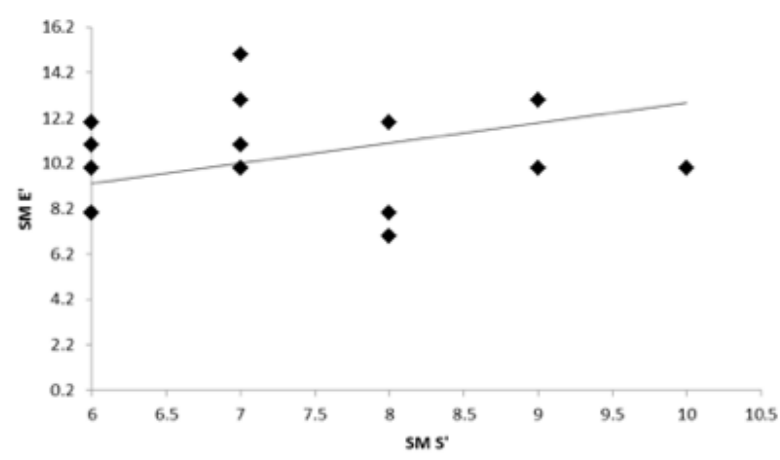

(b)

Figure (2): (a) Correlation between $\mathrm{S}^{\prime}$ and $\mathrm{E}^{\prime}$ waves of lateral aspect of mitral valve annuls among patients. (b) Correlation between $\mathrm{S}^{\prime}$ and $\mathrm{E}^{\prime}$ waves of septal aspect of mitral valve annuls among patients.

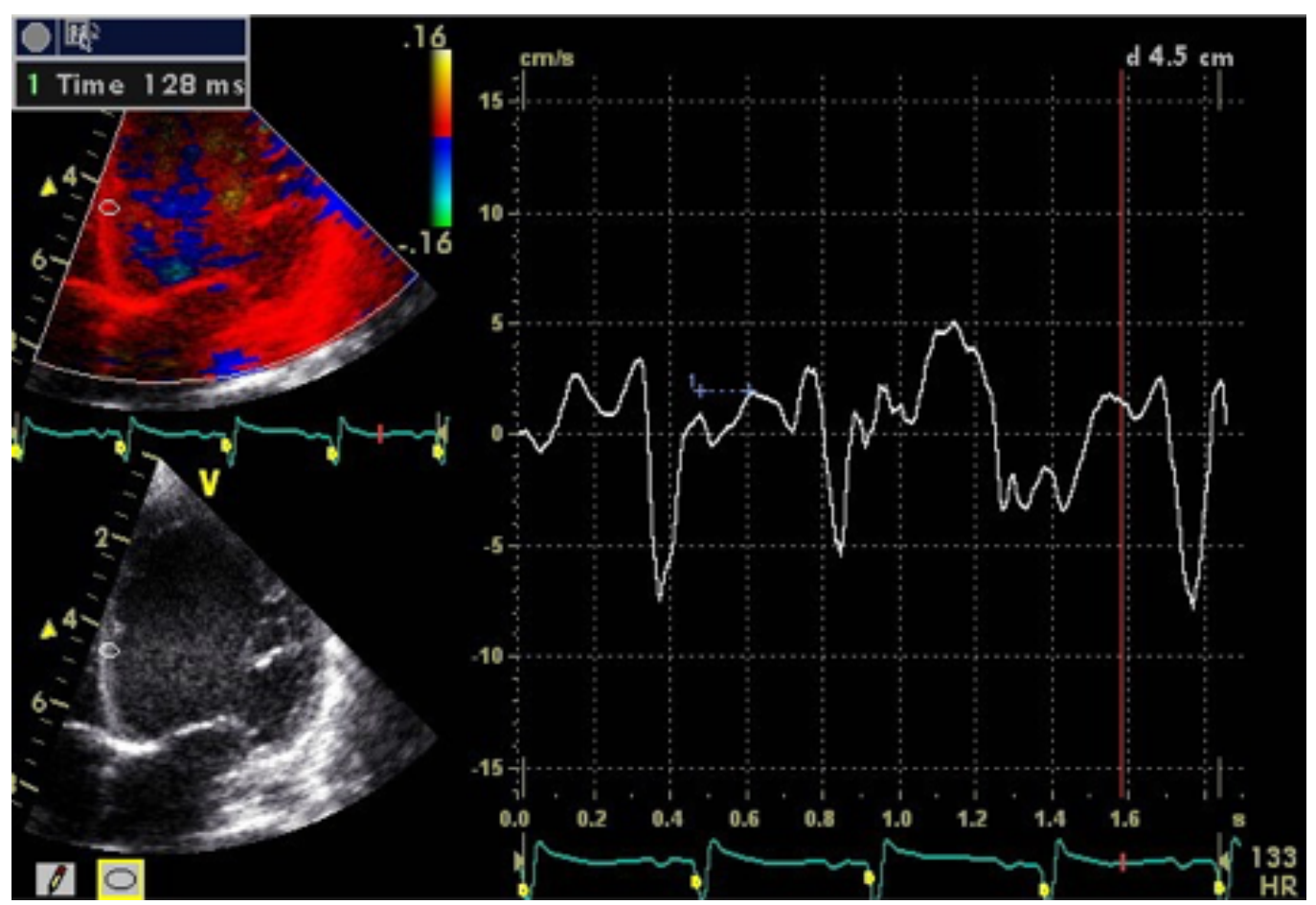

Figure (3): The time to peak measurement on the mid segment of the septal wall of the left ventricle in the 4 chamber view.

The time to peak systolic velocity was measured and standard deviation was calculated. The cases had higher TP-SD than controls in both the septal $( \pm 41.77)$ and lateral walls $( \pm 36.501)$ with no statistically significant difference (Table 4). Figure 3 shows how the TP was taken for septal and lateral walls. When comparing the TP-SD of the different walls of the left ventricles of the affected cases to each other, there were no statistical difference as well $(p=0.125)$ (Table 5).

The time to peak of all walls, SD in cases $( \pm 55.14)$ and in controls $( \pm 19.94)$ was not affected $(\mathrm{P}=0.683)$. It is worth noting that only one case died from our patients during follow up and this patient showed significantly higher TP in different walls of the left ventricle. 
Table 3. Comparison between patients and control group as regards the average peak systolic velocities of basal and mid points of 6 different LV walls.

\begin{tabular}{|c|c|c|c|}
\hline & & Mean \pm SD & $\begin{array}{c}P \\
\text { value }\end{array}$ \\
\hline \multirow{2}{*}{ Lateral wall } & Cases & $3.049 \pm 0.8896$ & \multirow{2}{*}{0.002} \\
\hline & Control & $5.503 \pm 2.3929$ & \\
\hline \multirow{2}{*}{ Posterior wall } & Cases & $3.392 \pm 1.0542$ & \multirow{2}{*}{0.001} \\
\hline & Control & $5.625 \pm 2.0931$ & \\
\hline \multirow{2}{*}{ Inferior wall } & Cases & $3.198 \pm 1.2378$ & \multirow{2}{*}{0.002} \\
\hline & Control & $4.841 \pm 1.09$ & \\
\hline \multirow{2}{*}{ Septal wall } & Cases & $3.75 \pm 0.9538$ & \multirow{2}{*}{0.004} \\
\hline & Control & $4.947 \pm 0.9707$ & \\
\hline \multirow{2}{*}{$\begin{array}{l}\text { Anteroseptal } \\
\text { wall }\end{array}$} & Cases & $3.385 \pm 1.1564$ & \multirow{2}{*}{0.001} \\
\hline & Control & $5.369 \pm 1.6141$ & \\
\hline \multirow{2}{*}{ Anterior wall } & Cases & $3.639 \pm 1.4034$ & \multirow{2}{*}{0.938} \\
\hline & Control & $3.689 \pm 1.2868$ & \\
\hline
\end{tabular}

Table 4. Comparison between cases and control group as regard TP of the lateral wall and the septal wall of the left ventricle.

\begin{tabular}{|c|c|c|c|c|c|c|c|c|}
\hline & \multicolumn{4}{|c|}{ Lateral TP } & \multicolumn{4}{|c|}{ Septal TP } \\
\hline & Mean & SD & Median & $\begin{array}{c}\text { I.Q } \\
\text { range }\end{array}$ & Mean & SD & Median & $\begin{array}{l}\text { I.Q. } \\
\text { range }\end{array}$ \\
\hline Cases & 32.22 & 36.50 & 32.22 & 18.075 & 36.4 & 41.7 & 27.00 & 27.9 \\
\hline Control & 37.20 & 36.07 & 25.30 & 16 & 40.55 & 33.02 & 31.05 & 18.5 \\
\hline Test (Z) & \multicolumn{4}{|c|}{-0.718} & \multicolumn{4}{|c|}{-0.469} \\
\hline$P$ value & \multicolumn{4}{|c|}{0.473} & \multicolumn{4}{|c|}{0.639} \\
\hline
\end{tabular}

I.Q. range: interquartile range.

The overall intra-observer mean weighted kappa $=+0.68$ (range SE kappa $=0.012-0.052)$ (substantial agreement) and the overall inter-observer mean weighted kappa was $=+0.55$ (range $\mathrm{SE}$ kappa $=0.011-0.043)$ (moderate agreement).

Table 5. Comparison between TP-SD of the Septal wall of the left ventricle and the lateral wall

\begin{tabular}{lccc}
\hline & Mean & SD & $\begin{array}{c}\boldsymbol{P} \\
\text { value }\end{array}$ \\
\cline { 1 - 3 } TP-Lat.SD & 32.220 & 36.071 & \multirow{2}{*}{0.125} \\
\hline TP-Septal SD & 40.530 & 33.020 & \\
\hline
\end{tabular}

TP: time to peak; SD: standard deviation.

\section{Discussion}

In the current study children with DCM showed borderline diastolic dysfunction. The patients studied by Abduch et al., 2012 displayed more profound diastolic dysfunction which can be attributed to the increased duration of their illness (10). The studied patients in the present work showed combined left ventricular systolic and diastolic dysfunction as their modified Tei index was $0.568 \pm 0.118$. Many authors reported similar findings (11-14) in different age groups.

Although several authors studied the time to peak systolic velocity as a marker of LV desynchrony $(7,15,16)$, up to our knowledge there are only 2 studies focused on LV regional systolic dysfunction $(16,17)$. In the current study regional peak systolic velocities demonstrated impaired peak systolic velocities of all left ventricular walls, but the impairment is more in mid left ventricular segments as compared to the base, and by multivariate analysis there was significant difference of peak systolic velocities of different LV walls which delineate variable 
degrees of LV affection. Therefore, the ineffective global contractile dysfunction of LV is not attributed only to variable time to peak systolic velocities, but also, to variability of the peak systolic velocity that can be attained by different LV segments.

Regional heterogeneity of LV function in non-ischemic DCM has been reported using echocardiography, tissue Doppler ultrasound, left ventriculography, cine MRI and radionuclide studies. However, none of these methods allow quantitative measurements of material contraction and deformation. The reported pattern of heterogeneity varies widely between patients, with reduced function noted in inferior, septal and anterior walls and segments of preserved function typically located in the lateral wall. Juilliere and co-workers suggested the presence of regional variations in left ventricular contractility and myocardial perfusion in idiopathic dilated cardiomyopathy and might result from an increase in left ventricular wall stress responsible for regional wall motion abnormalities $(16,18)$.

Nonhomogeneous systolic function has detrimental effects on ventricular performance since mechanical work is wasted stretching some regions at the expense of stroke volume. Possible mechanisms for functional heterogeneity include regional variations in afterload (wall stress), impaired relaxation, decreased contractile efficiency and perfusion defects $(16,18)$.

Hayashida with his team noted considerable regional variation using left ventriculography in the right anterior oblique view; however, no consistent patterns were observed, and the septum was not well visualized (19). Similarly, Sunnerhagen and his colleagues found abnormal wall motion in the apical and antero- apical regions using time-intensity curves from digitized right anterior oblique left ventriculograms $(20)$.

The systolic waves of septal and lateral aspects of mitral annulus of our studied patients were significantly lower than those of the control group. Furthermore, their values were significantly positively correlated with the early diastolic wave (E'). Mohamed and coworkers previously reported the same finding (21).

The relation between longitudinal systolic and diastolic velocities may reflect the contribution of longitudinal motion to diastolic filling as well as the longitudinal vector of torsional motion. During systole, there is twisting and shortening of the ventricle, and in diastole there is rapid untwisting and lengthening creating diastolic suction which promotes early filling $(22-24)$. On the other hand, the decrease in contractile function and especially the relaxation abnormalities likely stem from the myocardial disarray which may be a common pathological factor in the systolic and diastolic abnormalities in this disease. The systolic longitudinal contractile dysfunction is a possible cause of relaxation abnormalities in DCM and it correlation is enough to correct the diastolic abnormality (11).

TDI owing to its high spatial and temporal resolution is capable of sensitively reflecting the synchrony of LV contraction (25). Therefore, our study we aimed to detect any desynchrony in pediatric DCM patients. This was done by comparing the synchrony in each wall of the left ventricle comparing it to the controls and also comparing synchrony of the walls of the same ventricle.

Ts-SD and Ts-maxD in the $12 \mathrm{LV}$ segments of the DCM patients with congestive heart failure were significantly higher than those of the healthy controls $(\mathrm{P}<0.01)(26)$. Preliminary studies suggest that cardiac resynchronization therapy (CRT) will become an important therapeutic modality in the treatment of pediatric systolic heart failure from numerous etiologies. One of the first steps in developing CRT therapeutics in pediatrics is to understand population norms for the parameters being measured. Misra et al., in 2011 published a study of children with normal hearts suggesting that adult CRT desynchrony cutoff values are inappropriate in pediatric age patients (26). Studies are under way to develop heart rate and age appropriate indices of desynchrony in children as required first steps in efforts to better predict which segment of the pediatric heart failure population may benefit from this promising new therapy.

There is limited confidence in the data available regarding the extent of mechanical desynchrony in pediatric patients with systolic heart failure. This makes it difficult to even predict the potential population in which CRT may be effective (27).

Finally, the addressed subject has been tackled several times in many papers, the technique used is not the gold standard in this context however, the study offers a reasonable amount of 
significance as it uses a simpler and easily reproducible technique that can be easily repeated in low and middle income countries.

Our study has its limitations. Recently tissue Doppler may not be the optimal method of assessing LV desynchrony. The researchers are moving towards a combination of longitudinal and radial desynchrony measurement (tissue Doppler and speckle tracking). In addition, the time-to-peak of systolic velocity is angle-dependent and may be influenced by LV geometry. For this reason, Tp is not the gold standard for detection of desynchrony. The analysis of the data collected was by a post processing method instead of real time. Further studies using the electrophysiologic mapping methods to identify the exact electrical activity may be useful. Also, further studies are needed to study the efficacy of treatment and effect of variable etiologies.

Finally, the relatively limited number of cases in this study makes it difficult to generalize our findings. So further studies are needed to determine the predictive value of these findings.

\section{Conclusion}

Children with DCM have global systolic dysfunction and borderline diastolic dysfunctions which are correlated. The systolic dysfunction is variable among the different LV segments being more in the mid LV segments as compared to basal ones which may contribute to impairment of global systolic function more than the simple M-mode can tell.

LVSD in patients with DCM may be detected by intraventricular delay time and Ts-SD, both of which are measured by tissue Doppler echocardiography. In pediatric age group with DCM LV desynchrony may not be evident, probably due to short duration of illness. Therefore longer follow up durations ought to be scheduled.

\section{Author Contributions:}

Sedky Y. edited the manuscript and contributed in revision and writing the manuscript; EL Saiedi S.A. was the primary investigator and revised the whole manuscript; Habeeb N.M.M. revised the manuscript and reviewed medical literature; El Kaffas R.M.H. carried out the clinical analysis and data collection; Mona A. Gabre M.A. shared in data collection and analysis; Badr A.M. revision of final version of the manuscript; Mohamed S. Eid M. S. revised literature and editing, submitted the manuscript and corresponded until publication. All authors have read and agreed to the published version of the manuscript.

\section{FUNDING}

Authors declare there was no extramural funding provided for this study.

\section{CONFLICT OF INTEREST}

The authors declare no conflict of interest in connection with the reported study. Authors declare veracity of information.

\section{References}

1. S. Tenny, M. Varacallo, Evidence Based Medicine. (StatPearls Publishing; Treasure Island (FL), 2020; https://www.ncbi.nlm.nih.gov/books/NBK470182/).

2. P. Elliott, B. Andersson, E. Arbustini, Z. Bilinska, F. Cecchi, P. Charron, O. Dubourg, U. Kuhl, B. Maisch, W. J. McKenna, L. Monserrat, S. Pankuweit, C. Rapezzi, P. Seferovic, L. Tavazzi, A. Keren, Classification of the cardiomyopathies: a position statement from the european society of cardiology working group on myocardial and pericardial diseases. Eur. Heart J. 29, 270-276 (2007).

3. The SOLVD Investigators*, Effect of Enalapril on Survival in Patients with Reduced Left Ventricular Ejection Fractions and Congestive Heart Failure. N. Engl. J. Med. 325, 293302 (1991).

4. R. Mogelvang, P. Sogaard, S. A. Pedersen, N. T. Olsen, J. L. Marott, P. Schnohr, J. P. Goetze, J. S. Jensen, Cardiac Dysfunction Assessed by Echocardiographic Tissue Doppler Imaging Is an Independent Predictor of Mortality in the General Population. Circulation. 119, 2679-2685 (2009). 
5. Prutkin JM, Chen MA, Rho RW, Gill EA, Echocardiographic Assessment of Dyssynchrony for Predicting a Favorable Response to Cardiac Resynchronization Therapy. US Cardiol. 3, $1-5$ (2006).

6. K. S. Dujardin, C. Tei, T. C. Yeo, D. O. Hodge, A. Rossi, J. B. Seward, Prognostic value of a doppler index combining systolic and diastolic performance in idiopathic-dilated cardiomyopathy. Am. J. Cardiol. 82, 1071-1076 (1998).

7. C.-M. Yu, E. Chau, J. E. Sanderson, K. Fan, M.-O. Tang, W.-H. Fung, H. Lin, S.-L. Kong, Y.-M. Lam, M. R. S. Hill, C.-P. Lau, Tissue Doppler Echocardiographic Evidence of Reverse Remodeling and Improved Synchronicity by Simultaneously Delaying Regional Contraction After Biventricular Pacing Therapy in Heart Failure. Circulation. 105, 438445 (2002).

8. H. Bader, S. Garrigue, S. Lafitte, S. Reuter, P. Jaïs, M. Haïssaguerre, J. Bonnet, J. Clementy, R. Roudaut, Intra-left ventricular electromechanical asynchrony. J. Am. Coll. Cardiol. 43, 248-256 (2004).

9. C.-M. Yu, Q. Zhang, J. W.-H. Fung, H. C.-K. Chan, Y.-S. Chan, G. W.-K. Yip, S.-L. Kong, H. Lin, Y. Zhang, J. E. Sanderson, A novel tool to assess systolic asynchrony and identify responders of cardiac resynchronization therapy by tissue synchronization imaging. J. Am. Coll. Cardiol. 45, 677-684 (2005).

10. M. C. D. Abduch, I. Salgo, W. Tsang, M. L. C. Vieira, V. Cruz, M. Lima, J. M. Tsutsui, V. Mor-Avi, R. M. Lang, W. Mathias Jr, Deformação miocárdica pelo speckle tracking na cardiomiopatia dilatada grave. Arq. Bras. Cardiol. 99, 834-843 (2012).

11. C. J. McMahon, Echocardiographic predictors of adverse clinical events in children with dilated cardiomyopathy: a prospective clinical study. Heart. 90, 908-915 (2004).

12. O. Akpinar, A. Bozkurt, E. Acartürk, Reliability of Doppler Methods in the Evaluation of the Left Ventricular Systolic Function in Patients with Idiopathic Dilated Cardiomyopathy. Echocardiography. 24, 1023-1028 (2007).

13. Nicolin N, Mornos C, Ionac A, Mornos A, Pescariu S, Dragulescu I-S, The value of global myocardial index to detect cardiac dyssynchrony in patients with non-ischemic dilated cardiomyopathy. Stud. Univ. Vasile Goldis Ser. Stiintele Vietii. 2, 51-57 (2011).

14. M. K. Friedberg, S. L. Roche, A. F. Mohammed, M. Balasingam, E. G. Atenafu, P. F. Kantor, Left Ventricular Diastolic Mechanical Dyssynchrony and Associated Clinical Outcomes in Children With Dilated Cardiomyopathy. Circ. Cardiovasc. Imaging. 1, $50-57$ (2008).

15. T. Karaahmet, K. Tigen, B. Mutlu, C. Cevik, G. Kahveci, Y. Basaran, Determination of Left Ventricular Systolic Dyssynchrony by Tissue Doppler Echocardiography in Patients With Nonischemic Dilated Cardiomyopathy. Congest. Heart Fail. 15, 19-23 (2009).

16. A. Young, Regional heterogeneity of function in nonischemic dilated cardiomyopathy. Cardiovasc. Res. 49, 308-318 (2001).

17. D. S. Bach, R. S. B. Beanlands, M. Schwaiger, W. F. Armstrong, Heterogeneity of ventricular function and myocardial oxidative metabolism in nonischemic dilated cardiomyopathy. J. Am. Coll. Cardiol. 25, 1258-1262 (1995).

18. Y. Juilliere, P. Y. Marie, N. Danchin, C. Gillet, F. Paille, G. Karcher, A. Bertrand, F. Cherrier, Radionuclide assessment of regional differences in left ventricular wall motion and myocardial perfusion in idiopathic dilated cardiomyopathy. Eur. Heart J. 14, 11631169 (1993).

19. W. Hayashida, T. Kumada, R. Nohara, H. Tanio, M. Kambayashi, N. Ishikawa, Y. Nakamura, Y. Himura, C. Kawai, Left ventricular regional wall stress in dilated cardiomyopathy. Circulation. 82, 2075-2083 (1990).

20. K. S. Sunnerhagen, V. Bhargava, R. Shabetai, Regional left ventricular wall motion abnormalities in idiopathic dilated cardiomyopathy. Am. J. Cardiol. 65, 364-370 (1990).

21. A. Mohammed, L. Mertens, M. K. Friedberg, Relations Between Systolic and Diastolic Function in Children With Dilated and Hypertrophic Cardiomyopathy as Assessed by Tissue Doppler Imaging. J. Am. Soc. Echocardiogr. 22, 145-151 (2009).

22. Y. Notomi, Z. B. Popović, H. Yamada, D. W. Wallick, M. G. Martin, S. J. Oryszak, T. Shiota, N. L. Greenberg, J. D. Thomas, Ventricular untwisting: a temporal link between left ventricular relaxation and suction. Am. J. Physiol.-Heart Circ. Physiol. 294, H505-H513 (2008).

23. G. D. Buckberg, M. L. Weisfeldt, M. Ballester, R. Beyar, D. Burkhoff, H. C. Coghlan, M. Doyle, N. D. Epstein, M. Gharib, R. E. Ideker, N. B. Ingels, M. M. LeWinter, A. D. McCulloch, G. M. Pohost, L. J. Reinlib, D. J. Sahn, G. Sopko, F. G. Spinale, H. M. Spotnitz, F. Torrent-Guasp, E. P. Shapiro, Left Ventricular Form and Function: Scientific Priorities 
and Strategic Planning for Development of New Views of Disease. Circulation. 110 (2004), doi:10.1161/01.CIR.0000143625.56882.5C.

24. Y. Notomi, R. M. Setser, T. Shiota, M. G. Martin-Miklovic, J. A. Weaver, Z. B. Popović, H. Yamada, N. L. Greenberg, R. D. White, J. D. Thomas, Assessment of Left Ventricular Torsional Deformation by Doppler Tissue Imaging: Validation Study With Tagged Magnetic Resonance Imaging. Circulation. 111, 1141-1147 (2005).

25. A. Vitarelli, P. Franciosa, S. Rosanio, Tissue Doppler Imaging in the assessment of selection and response from cardiac resynchronization therapy. Eur. J. Echocardiogr. 8, 309-316 (2007).

26. N. Yi, S. Zhang, Left ventricular systolic synchrony in dilated cardiomyopathy patients with normal QRS wave. Zhong Nan Da Xue Xue Bao Yi Xue Ban. 35, 1023-1028 (2010).

27. M. K. Friedberg, N. H. Silverman, A. M. Dubin, D. N. Rosenthal, Mechanical Dyssynchrony in Children with Systolic Dysfunction Secondary to Cardiomyopathy: A Doppler Tissue and Vector Velocity Imaging Study. J. Am. Soc. Echocardiogr. 20, 756-763 (2007). 